\title{
Factors Associated to Health Needs from Homeless Perspective in Spain
}

\author{
David Martín-Baena ${ }^{1}$, Isabel Montero-Piñar ${ }^{2} \&$ María Isabel Fuertes-Lanzuela ${ }^{3}$ \\ ${ }^{1}$ CIBER Epidemiología y Salud Pública (CIBERESP), Spain \\ ${ }^{2}$ Faculty of Medicine, Department of Psychiatry, University of Valencia, Valencia, Spain \\ ${ }^{3}$ Nursing School "La Fe", Valencia, Pabellon Docente.Torre H, Bulevar Sur S/N, 46026, Spain \\ Correspondence: Dr. David Martín-Baena, Technical researcher, Ciber de Epidemiología y Salud Pública \\ (CIBERESP), FISABIO. Area Health Inequalities, Avda. Catalunya, 2146020 Valencia, Spain. Tel: 34-96-192 59 \\ 32. E-mail: martin_dav@gva.es
}

Received: December 7, 2016

Accepted: December 21, 2016 Online Published: December 23, 2016

doi:10.20849/ijsn.v1i1.102

URL: http://dx.doi.org/10.20849/ijsn.v1i1.102

\begin{abstract}
Purpose: This pilot study aims to identify factors associated to roofless own health self-perception.

Design: Cross-sectional study with a sample of homeless people $(n=68)$ who come for help to one of the homeless service centers founded by a non-profit organization. Socio-demographic characteristics, years living on streets, unhealthy habits, chronic morbidity, basic needs and self-reported physical and mental health were described. To identify factors related to mental and physical health from roofless own perspective, a binary logistic analysis was held.

Findings: The majority of participants were under 40 years, male and Spanish, alcohol or drug consumers, $80 \%$ have lived in the street for one to five years with high levels of pain and poor mental health conditions. Living on the street over a year, exposure to violence, lack of hygiene and female gender, affect negatively the own perception of physical and mental health conditions.

Conclusions: Our results show the different and complex homeless health needs. Given the duration of homelessness affected their health condition, recent roofless homeless should be identified as soon as possible.

Clinical relevance and further research: Those providing care for homeless people must promote a more coordinated care, maximizing flexibility and fostering relationships to better response to the multiple and different needs of this one vulnerable population. Further study is needed to allow identify the different experiences of homeless women and men.
\end{abstract}

Keywords: homeless, basic needs, physical health, mental health

\section{Introduction}

\subsection{Homelessness in Europe}

Homelessness is a multidimensional condition which affects many people in contemporary society, with health, economic, social and policies implications. The term homeless covers many types of insecure housing status including rough sleepers, newly arrived immigrants, people living in insecure, inadequate and overcrowded accommodation or living in emergency and temporary accommodation (Gelberg, Andersen, \& Leake, 2000). The lack of national level data in many European countries, together with the different definitions and approaches to data collection and measurement, makes unable to arrive to a unique estimation of the homelessness in Europe (Edgar, Doherty, \& Meert, 2003). The fourth review of statistics on homelessness in Europe proposes a typology of homelessness and housing exclusion, to improve research and policy decision-making on homelessness differentiating two categories of homelessness: "roofless" (sleeping rough or in emergency accommodation) and "houseless" (sleeping in hostels or other temporary accommodation) (Edgar $\&$ Meert, 2005).

The number of people experiencing homelessness over the last few years increases in all European countries, with the exception of Finland and the Netherlands (ENHW, 2013). More than 4 million people have had a homeless episode in the last year and more than 400,000 individuals are homeless on any one night in western 
countries (Fazel, Geddes, \& Kushel, 2014). Structural factors, as income inequality, promote homelessness, although migration within the EU and from outside countries, ageing of the population, changes in family structure, unemployment and unavailability of subsidized housing contribute to homelessness. The Spanish Statistic Institute estimated around 23.000 homeless people on a single night, representing the $0.05 \%$ of the Spanish population (National Institute of Statistics, 2012). Taken into account that the sample comprises only homeless from community free food services and sleeping shelters, in municipalities with more than 20,000 inhabitants, this estimation could at least rise up to 40,000 according to the last Spanish homeless report (Rais Foundation, 2015).

\subsection{Homelessness and Health}

Homelessness is a social problem with enormous public health significance. Literature consistently found that homeless people have a higher rate of serious morbidity compared to general population, regardless if they are chronically or not chronically unsheltered (Levitt, Culhane, DeGenova, O'Quinn, \& Bainbridge, 2009). Drug and alcohol dependence, mental health conditions and dual diagnosis are reported as the most common health needs among homeless (Martens, 2001; Wiersma et al., 2010). Stigma, prejudice and the inadequacy and complexity of services that they have to use, as opening hours -transportation and difficulties engaging with professionals (Mills, Burton, \& Matheson, 2015), represent barriers that prevent them from using health services, particularly primary care and mental health services (Chrystal et al., 2015).

Different models and services to address homeless health needs have been developed in many European countries (Kaoutar et al., 2014; Keogh, O'Brien, Hoban, O'Carroll, \& Fahey, 2015; Lester, Wright, Heath, \& RGCP Health Inequalities Standing Group, 2002), however staff with a professional qualification tends to be in a minority of organizations in a number of countries (Bhui, Shanahan, \& Harding, 2006). Despite the growing interest in homeless health's needs, knowledge of how homeless people perceive their own health's needs is poorly understood (Baggett, O’Connell, Singer, \& Rigotti, 2010).

\section{Research Aim}

This study aims to reduce this gap, through the analysis of their own health's needs. It is based on the explanations given by them, describing with their own voice their profile, basic needs, unhealthy habits, chronic mobility and self-related physical and mental health conditions.

\section{Methods}

\subsection{Design and Sample}

This cross-sectional pilot study uses a sample of homeless seeking for help from one of the homeless serving centres, founded by the non-profit Doctors of the World in Valencia City (Spain). The centre was staffed by voluntary nurses, social workers, psychologist and physicians with the collaboration of nonprofessional volunteers and offers day care for a maximum of six months. Team members provide rudimentary medical care and also focus on social work, helping homeless access to social security benefits, health insurance, residence cards and emergency shelters or permanent housing. Data were collected from those attending between February and April 2015, the period with the highest demand for shelter and food assistance registered in this Spanish region (National Institute of Statistics, 2013). After excluding those who did not understand the Spanish language, the number of homeless invited to participate were 68 and a $10.2 \%$ ( 5 men and 2 women) refused, so the final sample brings 61 homeless: $91.8 \%$ men and $8.2 \%$ women.

\subsection{Measurements}

Information was gathered using a structured interview based on literature and staff experience (Uribe \& Alonso, 2009). The interview covered different areas: a) socio-demographic characteristics; b) housing and family contact; c) unhealthy behaviors d) use of substances; e) chronic morbidity; f) self-perceived health status; physical and mental health conditions, and g) basic needs, based on Virginia Henderson's Needs Model (Henderson, 1997), adapted and reduced to suit basic homeless needs: rest, food, safety and hygiene. To assess homeless overall health state we used the short SF-12 version from the original SF-36 questionnaire, validated for different populations and recommended for homeless research (Larson, 2002). This tool includes measurements of physical health (subscale of physical components (PCS) and mental health state (mental components subscale (MCS). The Spanish version of the SF-12 has adequate psychometric properties and improved both the metric properties and interpretation of the original SF-36 questionnaire (Ware, Kosinski, \& Keller, 1996) with a reliability of $\alpha=.56$ for physical health and $\alpha=.53$ for mental health Cronbach's $\alpha$ coefficient and a validity of 0.94 , representing an explained variance of $88.36 \%$ (Vera-Villarroel, Silva, Celis-Atenas, \& 
Pavez, 2014). According to literature, reliabilities of 0.6 or 0.5 are suitable for early stages of research (Peduzzi, Concato, Kemper, Holford, \& Feinstein, 1996).

Interviews were conducted in the office after snack, shower and dinner times, combining with scheduled consultations and different activities held in the center. The purpose and interest of the study was explained and confidentiality and anonymity were guaranteed, informing that they could stop the interview at any time without any consequences on the attention or the care provided. After required verbal informed consent, the information was collected by a mental health nurse practitioner, who was independent of the research team.

\subsection{Analytic Strategy}

The sample size calculation offers a medium effect (i.e., $\mathrm{R}^{2}=0.15$ ) with alpha of .05 and $99 \%$ of power, figures than were considered satisfactory to ensure the statistical analysis (Cohen, 1977). Frequencies and standard Chi-squared test $(p<0.05)$ for categorical variables and mean and $t$ - Student for continuous were used for the descriptive analysis. To identify factors associated to health outcomes, binary logistic regression analysis was performed. Odds Ratio and its Confidence Interval (OR (95\% CI)) were calculated. Analyses were performed with the Statistical Program for the Social Sciences (SPSS) version 20.0.

\section{Results}

\subsection{Socio-demographic Characteristics}

Table 1. Social and demographics profile of the roofless sample $(n=61)$

\begin{tabular}{|c|c|c|}
\hline Variables & $n$ & $\%$ \\
\hline \multicolumn{3}{|l|}{ Age (in years) } \\
\hline $19-29$ & 12 & 19.7 \\
\hline $30-39$ & 21 & 34.4 \\
\hline $40-49$ & 18 & 29.5 \\
\hline $50-59$ & 8 & 13.1 \\
\hline$>60$ & 2 & 3.3 \\
\hline \multicolumn{3}{|l|}{ Gender } \\
\hline Men & 56 & 91.8 \\
\hline Women & 5 & 8.2 \\
\hline \multicolumn{3}{|l|}{ Region of Origin } \\
\hline Spain & 31 & 50.8 \\
\hline Eastern Europe & 14 & 22.9 \\
\hline Africa & 13 & 21.3 \\
\hline South America & 3 & 4.9 \\
\hline \multicolumn{3}{|l|}{ Education- } \\
\hline Elementary School & 28 & 45.9 \\
\hline Medium/High School & 33 & 54.1 \\
\hline \multicolumn{3}{|l|}{ Source of income * } \\
\hline Irregular activity & 37 & 60.7 \\
\hline State aid & 9 & 14.8 \\
\hline Begging & 5 & 8.2 \\
\hline \multicolumn{3}{|l|}{ Living on street } \\
\hline$<1$ year & 22 & 36.1 \\
\hline $1-5$ years & 28 & 45.9 \\
\hline$>5$ years & 11 & 18.0 \\
\hline \multicolumn{3}{|l|}{ Sleeping } \\
\hline In streets or parks & 19 & 31.1 \\
\hline In subway platforms & 12 & 19.7 \\
\hline In "building halls" & 30 & 49.2 \\
\hline Without health coverage & 16 & 26.2 \\
\hline \multicolumn{3}{|l|}{ Social Contact } \\
\hline With family & 49 & 80.3 \\
\hline With partner & 16 & 26.2 \\
\hline
\end{tabular}

*Missing values 
Table 1 shows the socio-demographic sample profile. Most homeless are Spanish, followed by people from Eastern Europe and North Africa, men, aged less than 40 years and $54.1 \%$ have completed medium or high school. Of the 61 homeless surveyed, $45.9 \%$ have lived in the streets from one to five years, and the $31.1 \%$ sleep outdoors (on streets or parks) and the rest in emergency accommodation (subway platforms or buildings halls). For most of them, income comes from irregular activities and in $8.2 \%$ from begging and only $14.8 \%$ from social benefits. The $26.2 \%$ don't have health coverage and most maintain contact with their families and the $26.2 \%$ with a stable partner.

\subsection{Unhealthy Behaviors and Chronic Morbidity}

Table 2. Unhealthy habits and chronic morbidity $(n=61)$

\begin{tabular}{lcc}
\hline Variables & $n$ & $\%$ \\
\hline Unhealthy habits & & \\
Substance consume (last months) & 54 & 88.5 \\
Tobacco & 44 & 72.1 \\
Alcohol & 47 & 77.0 \\
$\quad$ Illicit drugs & 23 & 37.7 \\
$\quad$ Cannabis & 13 & 21.3 \\
$\quad$ Cocaine & 4 & 6.6 \\
$\quad$ Heroin & 7 & 11.5 \\
$\quad$ Benzodiazepines (not prescribed) & & \\
Risk behaviors & 30 & 49.2 \\
Unprotected sex & 0 & 0.0 \\
Share syringes & & \\
Chronic morbidity & 3 & 4.9 \\
HIV/AIDS & 12 & 19.7 \\
Hepatitis & 2 & 3.3 \\
TB & 6 & 9.8 \\
Chronic asthma/bronchitis & 3 & 4.9 \\
Diabetes & 55 & 90.2 \\
Pain* & 36 & 59.0 \\
$\quad$ Back & 26 & 42.6 \\
Feet & 29 & 47.5 \\
$\quad$ Mouth & 17 & 29.5 \\
$\quad$ Stomach & 23 & 37.7 \\
Mental health conditions & & \\
\hline
\end{tabular}

* Not mutually exclusive

The vast majority are current smokers, $77 \%$ drug users and $72.1 \%$ alcohol drinkers. Cannabis is the drug most commonly consumed (37.7\%), followed by cocaine (21.3\%) and not prescribed benzodiazepines (11.5\%). Heroine was consumed less than other drugs $(6.6 \%)$ and no one injecting drugs ever reused or exchanged syringes. Of the participants who had sex, either with a steady or a causal partner, the $49.2 \%$ did not use any kind of protection on every occasion. The most common physical health problem was pain $(90.2 \%)$, especially back pain $(59.0 \%)$ and mouth/gums and teeth (47.5\%). Hepatitis (19.7\%), asthma and chronic bronchitis is also common (9.8\%), while HIV/AIDS and tuberculosis is less frequent in our sample, $4.9 \%$ and $3.3 \%$ respectively (Table 2).

\subsection{Basic Needs and Self-Perceived Health}

Need for sleep and rests was reported by the $75.4 \%$ and unsafety was stated by the $80 \%$. Of them, the $23 \%$ have been victims of street fights, $27.9 \%$ of assaults and $34 \%$ of thefts. Most of them eat once (39.3\%) or even twice a day $(42.6 \%)$, whereas $11(18.1 \%)$ do not eat every day. Food intake consists mainly of bread, bakery products and cold meals, where vegetables, meat, fish, eggs and dairy products were markedly absent. Lack of hygiene was also reported as one of the basic unmet needs by the $34.4 \%$ of the roofless surveyed. Although $42.6 \%$ of the homeless perceived their overall health state as good, $59.0 \%$ perceived poor physical health and $50.8 \%$ poor mental health conditions (Table 3). 
Table 3. Health and basic needs from homeless perspective $(n=61)$

\begin{tabular}{lcc}
\hline Variables & $n$ & $\%$ \\
\hline Self-perceived Health & & \\
Overall health status & & \\
$\quad$ Good & 26 & 42.6 \\
$\quad$ Poor & 35 & 57.4 \\
Physical health & & \\
$\quad$ Good & 25 & 41.0 \\
$\quad$ Poor & 36 & 59.0 \\
Mental health & & \\
$\quad$ Good & 30 & 49.2 \\
$\quad$ Poor & 31 & 50.8 \\
Unmet basic needs & & \\
Sleep and Rest & 46 & 74.7 \\
Safety & 52 & 85.0 \\
$\quad$ Fights & 14 & 23.0 \\
$\quad$ Assaults & 17 & 27.9 \\
$\quad$ Thefts & 21 & 34.4 \\
Food intake & & \\
Mails per day & & \\
$\quad$ None & 11 & 18.1 \\
$\quad$ One & 24 & 39.3 \\
$\quad$ Two & 26 & 42.6 \\
Diet & & \\
$\quad$ Bread, bakery products and cold meals & 54 & 88.5 \\
$\quad$ Vegetables, meat, fish, eggs and dairy & 7 & 11.4 \\
$\quad$ products & & \\
Hygiene & 21 & 34.4 \\
\hline Total differ by missg & & \\
\hline
\end{tabular}

Total differ by missing values

\subsection{Factors Associated to Physical and Mental Health}

Table 4 shows the results of the binary logistic analysis. Roofless women are more likely to report poor overall health state than roofless men $(\mathrm{OR}=1.80)$. Those who live in the streets (from one to five years) are more likely to perceive poor health $(\mathrm{OR}=3.45)$ compared to those who live in the streets less than a year. Unsafe homeless people are near to four times more likely to perceived poor mental health than homeless who don't report unsafety $(3.91 \%)$. Hygiene also appears strongly associated with poor physical health $(\mathrm{OR}=4.52)$.

Table 4. Factors associated with physical and mental health: Logistic Regression Models

\begin{tabular}{|c|c|c|c|c|c|c|}
\hline \multirow[b]{2}{*}{ Variables } & \multicolumn{2}{|c|}{ Poor overall health } & \multicolumn{2}{|c|}{ Poor physical health } & \multicolumn{2}{|c|}{ Poor mental health } \\
\hline & $\mathrm{n}(\%)$ & OR $(95 \% \mathrm{CI})$ & $\mathrm{n}(\%)$ & OR $(95 \% \mathrm{CI})$ & $\mathrm{n}(\%)$ & OR $(95 \% \mathrm{CI})$ \\
\hline \multicolumn{7}{|l|}{ Gender } \\
\hline Men & $28(53.8)$ & 1 & $34(60.7)$ & 1 & $30(53.6)$ & 1 \\
\hline Women & $5(100)$ & $1.80 *(1.44-2.38)$ & $2(40.0)$ & $2.31(0.35-15.0)$ & $1(20.0)$ & $2.58(0.27-24.7)$ \\
\hline \multicolumn{7}{|c|}{ Years living in streets } \\
\hline$<1$ year & $8(38.1)$ & 1 & $14(63.6)$ & 1 & $10(45.5)$ & 1 \\
\hline $1-5$ years & $17(68.0)$ & $3.45 *(1.02-11.6)$ & $14(50.0)$ & $0.57(0.18-1.79)$ & $14(50.0)$ & $0.97(0.30-3.11)$ \\
\hline$>5$ years & $8(72.7)$ & $4.33(0.88-21.3)$ & $8(72.7)$ & $1.52(0.31-7.44)$ & $7(63.6)$ & $1.45(0.33-6.34)$ \\
\hline Sleep and Rest & $24(55.8)$ & $1.31(0.45-3.80)$ & $26(56.5)$ & $0.96(0.34-2.69)$ & $23(50.0)$ & $1.01(0.36-2.87)$ \\
\hline Safety & $16(48.5)$ & $1.11(0.38-3.19)$ & $21(58.3)$ & $2.48(0.87-7.12)$ & $16(69.6)$ & $3.91 *(1.29-11.8)$ \\
\hline Hygiene & $13(68.4)$ & $1.95(0.61-6.90)$ & $13(61.9)$ & $4.52 *(1.20-16.87)$ & $13(61.9)$ & $1.39(0.47-4.10)$ \\
\hline Food intake & $14(46.7)$ & $0.36(0.12-1.10)$ & $18(54.5)$ & $0.66(0.23-1.87)$ & $15(45.5)$ & $0.50(0.17-1.43)$ \\
\hline
\end{tabular}




\section{Discussion}

Sample profile corresponds to Spanish men, alcohol and drug consumers, living in the streets for years and sleeping rough or in emergency accommodations. As in most European countries the age group of 30 to 49 years is the largest group of homeless (Busch-Geertsema, Benjaminsen, Hrast, \& Pleace, 2014), comprising 63.9\% in our sample, where the $19.7 \%$ are younger than 30 and only $3 \%$ aged 60 or over. This profile confirms that current homeless differ from the old homeless described by Rossi (1990): they are younger, poorer and with less access to sleeping shelters or cheap hostels that old homeless. The current recession in Europe generated increased poverty and inequalities and the lack of funds to help the most vulnerable population has led many municipalities to restrict access to housing and support for homeless people, where $34 \%$ of the homeless in Spain sleep outside the care network (FEANTSA, 2006).

Research consistently shows that over a third of individuals who are homeless experience alcohol and drug problems, although results varied by studies. A previous study conducted in Ireland found that a third of homeless had been diagnosed with an addiction, predominantly related to drugs $(72 \%)$, with smaller numbers diagnosed with an addiction to alcohol (28\%) (Keogh et al., 2015). Instead, we found a much higher percentage of alcohol drinkers $(71.2 \%)$, similar to that found in a Spanish previous study, where the $74.7 \%$ were current drinkers (Uribe \& Alonso, 2009). The fact that alcohol is easily accessible and fairly cheap can influence increased consumption of alcohol by homeless in Spain. Changing prices and its availability and offering a cost-effective approach could improve treatment abstinence among addicted alcohol homeless, since the incremental cost of these programs is within a reasonable range compared to other common societal interventions (Schumacher, Mennemeyer, Milby, Wallace, \& Nolan, 2002).

Cannabis is the most popular drug used, high above cocaine and heroin. Among those ever injecting drugs, none reused or exchanged syringes in the last month, contrary to that found in a previous study where of the $44 \%$ of homeless ever injecting drugs, 56\% reused their own needle and the 39\% used it from somebody else (Keogh et al., 2015). In Spain, as well as in other European countries, a legal framework that allows the distribution of sterile needles and syringes to drug users to minimize health risks, particularly for hepatitis $\mathrm{C}$ and HIV/AIDS was adopted. The prevalence of tobacco smoking among homeless people can reach more than $90 \%$ (Garner \& Ratschen, 2013). Spain is the ninth country in the EU with the highest percentage of smokers. Despite the reduction of four points between 2012 and 2014 in Spain, the number of smokers in homeless individuals has not decreased, where the $88.5 \%$ of roofless in our sample are current smokers.

Most Spanish organizations working with homeless population come to the conclusion that health self-perception is not a good method to obtain information for this specific population. This statement is based on the Spanish Homeless Report (ENHW, 2013), where 30.7\% of homeless surveyed had a serious or chronic illness, but only $14.2 \%$ perceived their health as poor, which leads them to assert that it is not a reliable tool to detect homeless health's needs. By contrast, we found that of the $67 \%$ of homeless with chronic health problems, $57.9 \%$ considered their overall health state as poor. These discrepant results may be influenced by the information provided by staff helping homeless to better recognize their own health condition than from samples selected in different points as community dining rooms or shelters. Nevertheless, the high chronic morbidity found confirms that roofless have a higher rate of serious morbidity compared to other underserved population.

Prevalence of mental disorders in homeless western countries is higher than among general population, but rates vary from $80-95 \%$ in USA, Australia, Canada, Norway, and Germany to $25-33 \%$ in Ireland and Spain (Fazel, Khosla, Doll, \& Geddes, 2008). Despite having to be cautious given the different tools used to assess outcome measurements, our results support the higher rates of self-related mental health among roofless (50.8\%) compared to the $25 \%$ found in adult Spanish general population (Haro et al., 2006). It is an ongoing need to focus on mental health issues that disproportionately affect homeless people. A systematic review study evaluating the effectiveness of interventions to improve the mental health of the homeless concludes that coordinated programs and case management improve the mental health of homeless rather than the usual attention (Hwang, Tolomiczenko, Kouyoumdjian, \& Garner, 2005).

Results show that living in the streets over a year has serious detrimental effects on homeless health, therefore it is a priority to identify recent and young roofless as soon as possible. Although the results should be interpreted with caution, due to the wide confidence intervals, the high frequency of incidents of violence and the strong association with serious physical and mental health conditions, requires more attention, as roofless are less safe than other disadvantaged collectives. Food intake is usually poor and unbalanced among homeless. It is characterized by high saturated fats, with deficiencies in proteins and micronutrients, which can have negative 
effects on physical and mental health (Seale, Fallaize, \& Lovegrove, 2016). Despite the lack of statistical significance between homeless nutrition and self-perceived health, the provision of adequate nutritional quality food remains a public health priority. The high number of roofless with mouth/gum/tooth pain requires providing free oral health services. Given that we found that living in the streets for a year has serious detrimental health effects, it is urgent to focus on young people starting homelessness, as they are exposed to more risks.

Health and health care disparities for the homeless are particularly distressing for homeless women (Teruya et al., 2010). Compared with general population, homeless women's health disparities include higher rates of mortality, more chronic morbidity, poor mental illness, substance abuse, victimization and poor birth outcomes (Crawford, Trotter, Hartshorn, \& Whitbeck, 2011). Since research has not been undertaken only with homeless women, their perception for health's needs is unknown. Despite the low number of roofless women in our sample, all of them perceived their overall health as poor, in contrast to the $53.8 \%$ of roofless men. As health is different for men and women, both in quality and quantity (Montero et al., 2004), with different profile and needs for homeless women than for homeless men (North \& Smith, 1993), the Committee on health care for underserved women calls for homeless intervention health programs including the gender perspective in order to provide more effective care for homeless women (Committee on health care for underserved women, 2013).

Interventions to improve homeless health has received significant attention over the past five years (Fitzpatrick-Lewis et al., 2011), but trials assessing the effectiveness of health interventions tailor to different types and needs of roofless people, remain scarce. Homeless are more likely to receive health care in countries with universal access to the health system than those who do not. Although Spain has universally and free access to the health system, during the financial crisis it has been denied for people without health coverage, except for emergency rooms, setting that contributes substantially to high health care costs and represents an inefficient use of health care resources (Milbrett \& Halm, 2009). The inclusion of homeless in the health system with accessibility and availability to primary health care and ensuring that they receive help with the complex admission procedures that they often face, is a pre-requisite for effective health interventions.

\subsection{Limitations}

The main limitation of this study was the sample size. The exclusion of homeless that did not understand the language has excluded an undetermined number of immigrants homeless, so outcomes could be underestimated. The cross-sectional nature of data implies that the causal direction of the effect of variables analyzed and health outcomes is not conclusive; although results seem to support that homelessness is the cause and not the effect. Given that we focus of homeless sleeping outside the care network and most living in streets for years, the generalization to other homeless profiles is very limited. Unfortunately the small number of roofless women does not allow a more detailed analysis, and should be considered in further studies.

\subsection{Conclusions}

Despite these limitations, this study provides new information on health's needs of homeless who have been living in the streets for years, where face-to-face interviews are usually hard to fill. Understanding the experiences of roofless people and meeting the needs of the homeless needs can help organizations that provide services to homeless people, to take better clinical decisions to respond to the multiple and different health needs of these vulnerable people. Future studies should address the diversity of homeless population with particular focus on women and recent roofless as they are at greatest risk of suffering from poor health.

\section{References}

Baggett, T.P., O'Connell, J., Singer, D.E., \& Rigotti, N.A. (2010). The unmet health care needs of homeless adults: A National Study. American Journal Public Health, 100(7), 1326-1333. http://dx.doi.org/10.2105/AJPH.2009.180109

Bhui, K., Shanahan, L., \& Harding, G. (2006). Homelessness and mental illness: a literature review and a qualitative study of perceptions of the adequacy of care. The International Journal of Social Psychiatry, 52(2), 152-165. http://dx.doi.org/10.1177/0020764006062096

Busch-Geertsema, V., Benjaminsen, L., Hrast, M.F., \& Pleace, N. (2014). Extent and Profile of Homelessness in European Member States. EOH Comparative Studies on Homelessness. Retrieved from http://www.feantsaresearch.org/IMG/pdf/feantsa-studies 04-web2.pdf

Chrystal, J.G., Glover, D.L., Young, A.S., Whelan, F., Austin, E.L., Johnson, N.K., ... Kertesz, S.G. (2015). Experience of primary care among homeless individuals with mental health conditions. PLoS One, 10(2), e0117395. http://dx.doi.org/10.1371/journal.pone.0117395

Cohen, J. (1977). Statistical power analysis for the behavioral sciences (rev. ed.). New York: Academic Press. 
Committee on health care for underserved women. (2013). Committee Opinion No. 576: Health care for homeless women. Obstetrics and Gynecology, 122(4), 936-940. http://dx.doi.org/10.1097/01.AOG.0000435417.29567.90

Crawford, D.M., Trotter, E.C., Hartshorn, K.J., \& Whitbeck, L.B. (2011). Pregnancy and mental health of young homeless women. American Journal of Orthopsychiatry, 81(2), 173-183. $\mathrm{http}: / / \mathrm{dx}$. doi.org/10.1111/j.1939-0025.2011.01086.x

Edgar, B., \& Meert, H. (2005). Fourth review of statistics on homelessness in Europe. The ETHOS definition of homelessness. $\quad$ Retrieved $\mathrm{http} / / / \mathrm{www}$. feantsaresearch.org/IMG/pdf/2005_fourth_review_of_statistics.pdf

Edgar, B., Doherty, J., \& Meert, H. (2003). Review of statistics on homelessness, 2003. Retrieved from http://www.homelesspages.org.uk/prods/products.asp?prid=2032

European Federation of National Organizations (FEANTSA). (2006). European Federation of National Organizations working with the Homeless, Health and Homelessness in Spain. Annual Report. Retrieved from http://www.noticiaspsh.org/spip.php?rubrique113

European Network of Homeless Health Workers (ENHW). (2013). Values that underpin the ENHW. Retrieved from http://www.feantsa.org/

Fazel, S., Geddes, J.R., \& Kushel, M. (2014). The health of homeless people in high-income countries: descriptive epidemiology, health consequences, and clinical and policy recommendations. Lancet, 384(9953), 1529-1540. http://dx.doi.org/10.1016/S0140-6736(14)61132-6

Fazel, S., Khosla, V., Doll, H., \& Geddes, J. (2008). The prevalence of mental disorders among the homeless in western countries: systematic review and meta-regression analysis. PLoS Medicine, 5(12), e225. http://dx.doi.org/10.1371/journal

Fitzpatrick-Lewis, D., Ganann, R., Krishnaratne, S., Ciliska, D., Kouyoumdjian, F., \& Hwang, S.W. (2011). Effectiveness of interventions to improve the health and housing status of homeless people: a rapid systematic review. BMC Public Health, 11, 638. http://dx.doi.org/10.1186/1471-2458-11-638

Garner, L., \& Ratschen, E. (2013). Tobacco smoking, associated risk behaviours, and experience with quitting: a qualitative study with homeless smokers addicted to drugs and alcohol. BMC Public Health, 13, 951. http://dx.doi.org/10.1186/1471-2458-13-951

Gelberg, L., Andersen, R.M., \& Leake, B.D. (2000). The Behavioral Model for Vulnerable Populations: application to medical care use and outcomes for homeless people. Health Service Research, 34(6), 1273-1302.

Haro, J.M., Palacín, C., Vilagut, G., Martínez, M., Bernal, M., Luque, I., ... Alonso, J. (2006). Prevalence of mental disorders and associated factors: results from the ESEMeD-Spain study. Medicina Clinica (Barc), 126(12), 445-451.

Henderson, V. (1997). ICN basic principles of nursing care. Retrieved from http://nursingworld.org/books

Hwang, S.W., Tolomiczenko, G., Kouyoumdjian, F.G., \& Garner, R.E. (2005). Interventions to improve the health of the homeless: A systematic review. American Journal of Preventive Medicine, 29(4), 311-333.

Kaoutar, B., Gatin, B., de Champs-Leger, H., Vasseur, V., Aparicio, C., de Gennes, C., ... Georges, C. (2014). Socio-demographic characteristics and health status of patients at a free-of-charge outpatient clinic in Paris. La Revue de Medecine Interne, 35(11), 709-714. http://dx.doi.org/10.1016/j.revmed.2014.05.013

Keogh, C., O'Brien, K.K., Hoban, A., O'Carroll, A., \& Fahey, T. (2015). Health and use of health services of people who are homeless and at risk of homelessness who receive free primary health care in Dublin. BMC Health Services Research, 15, 58. http://dx.doi.org/10.1186/s12913-015-0716-4

Larson, C.O. (2002). Use of the SF-12 instrument for measuring the health of homeless persons. Health Service Research, 37(3), 733-750. http://dx.doi.org/10.1111/1475-6773.00046

Lester, H., Wright, N., Heath, I., \& RGCP Health Inequalities Standing Group. (2002). Developments in the provision of primary health care for homeless people. The British Journal of General Practice, 52(475), 91-92.

Levitt, A., Culhane, D.P., DeGenova, J., O'Quinn, P., \& Bainbridge, J. (2009). Health and social characteristics of homeless adults in Manhattan who were chronically or not chronically unsheltered. Psychiatric Services, 60(7), 978-981. http://dx.doi.org/10.1176/appi.ps.60.7.978 
Martens, W.H. (2001). A review of physical and mental health in homeless persons. Public Health Reviews, 29(1), 13-33.

Milbrett, P., \& Halm, M. (2009). Characteristics and predictors of frequent utilization of emergency services. Journal of Emergency Nursing, 35(3), 191-198. http://dx.doi.org/10.1016/j.jen.2008.04.032

Mills, E.D., Burton, C.D., \& Matheson, C. (2015). Engaging the citizenship of the homeless- a qualitative study of specialist primary care providers. Family Practice, 32(4), 462-467. http://dx.doi.org/10.1093/fampra/cmv036

Montero, I., Aparicio, D., Gomez-Beneyto, M., Moreno-Küstner, B., Reneses, B., Usall, J., Vázquez-Barquero, J.L., \& Sociedad Española de Epidemiología Psquiátrica. (2004). Gender and mental health in a changing world. Gaceta Sanitaria, 18(1), 175-181.

National Institute of Statistics. (2012). Survey on the Homeless-People. Retrieved from http://www.ine.es/daco/daco42/epsh/cuesti_epshper.pdf

National Institute of Statistics. (2013). The homeless serving center survey. Retrieved from http://www.ine.es/dyngs/INEbase/es/operacion.htm?c=Estadistica_C\&cid=1254736176817\&menu=ultiDat os\&idp $=1254735976608$

North, C.S., \& Smith, E.M. (1993). A comparison of homeless men and women: different populations, different needs. Community Mental Health Journal, 29(5), 423-431.

Peduzzi, P., Concato, J., Kemper, E., Holford, T.R., \& Feinstein, A.R. (1996). A simulation study of the number of events per variable in logistic regression analysis. Journal of Clinical Epidemiology, 49(12), 1373-1379. http://dx.doi.org/10.1016/S0895-4356(96)00236-3

Rais Foundation for homeless people. (2015). Social exclusion and disability survey. Retrieved from https://www.raisfundacion.org/index.html\#1

Rossi, P.H. (1990). The old homeless and the new homelessness in historical perspective. The American Psychologist, 45(8), 954-959.

Schumacher, J.E., Mennemeyer, S.T., Milby, J.B., Wallace, D., \& Nolan, K. (2002). Costs and effectiveness of substance abuse treatments for homeless persons. The Journal of Mental Health Policy and Economics, 5(1), $33-42$.

Seale, J.V., Fallaize, R., \& Lovegrove, J.A. (2016). Nutrition and homeless: the underestimated challenge. Nutrition Research Reviews, 28, 1-9.

Shinn, M. (2007). International homelessness: Policy, socio-cultural, and individual perspectives. Journal of Social Issues, 63(3), 657-677. http://dx.doi.org/10.1111/j.1540-4560.2007.00529.x

Teruya, C.H., Longshore, D., Andersen, R.M., Arangua, L., Nyamathi, A., Leake, B., \& Gelberg, L. (2010). Health and Health Care Disparities among Homeless Women. Women \& Health, 50(8), 719-736. http://dx.doi.org/10.1080/03630242.2010.532754

Uribe, J., \& Alonso, S. (2009). People experiencing homelessness in Barcelona: Profiles, health status and health care. Barcelona: Brothers of Saint John of God.

Vera-Villarroel, P., Silva, J., Celis-Atenas, K., \& Pavez, P. (2014). Evaluation of the SF-12. Usefulness of the mental health scale. Revista Medica de Chile, 142(10), 1275-1283. http://dx.doi.org/10.4067/S0034-98872014001000007

Ware, J., Kosinski, M., \& Keller, S.D. (1996). A 12-Item Short-Form Health Survey: construction of scales and preliminary tests of reliability and validity. Medical Care, 34(3), 220-233.

Wiersma, P., Epperson, S., Terp, S., LaCourse, S., Finton, B., Drenzek, C., Arnold, K., \& Finelli, L. (2010). Episodic Illness, Chronic Disease, and Health Care Use among Homeless Persons in Metropolitan Atlanta, GA. Southern Medical Journal, 103(1), 18-24. http://dx.doi.org/10.1097/SMJ.0b013e3181c46f79

\section{Copyrights}

Copyright for this article is retained by the author(s), with first publication rights granted to the journal.

This is an open-access article distributed under the terms and conditions of the Creative Commons Attribution license (http://creativecommons.org/licenses/by/4.0/). 